\title{
Personal Pronoun Revisionism - Asking the Right Question
}

Personal pronoun revisionism (so-called by Eric Olson his book (2007)) is a response to the problem of the thinking animal (also called the 'too many minds' or 'too many thinkers' problem) on behalf of the neo-Lockean psychological continuity theorist. In this note I address a worry that many have felt about this response. The worry rests, I suggest, on asking the wrong question.

The problem of the thinking animal, briefly, is that it seems indisputable that human animals, i.e., human beings, or at least, all normal healthy adult human beings, are thinkers. But so, by definition, are persons. However, according to the neo-Lockean, persons are not human beings (they differ in their persistence conditions). So the neoLockean theory entails the existence of too many thinkers. Moreover, it creates an irresoluble epistemic problem: how do I know that I am the person sitting here thinking truly that he is a person and not the coincident human animal thinking falsely that he is a person? Finally, if human animals, in addition to persons, are thinkers, they must be persons after all, since their thoughts have whatever complexity and sophistication any ordinary definition of 'person' could require - they have just the same thoughts, after all, as the persons with whom, on the psychological continuity account, they 'cohabit', so the neo-Lockean's attempt to identify the persistence conditions for persons collapses into incoherence since he has to acknowledge different kinds of person with different persistence conditions - as it were person-persons and animal-persons.

The first-person pronoun revisionist says that in cases where the person and animal diverge in their histories, because the animal comes into existence before the person or goes out of existence later or because the two go their separate ways at some 
point, the temporarily coincident person and animal are indeed two thinkers - the multiplicity is accepted - but that only the persons thinks of himself in the first-person way. The animal has and expresses first-person thoughts, but these thoughts are not about him, but about the person with whom he coincides. Hence there is no epistemic worry since the question whether I am a person or an animal answers itself, and there is no worry that we must say that there are two persons present, since there is a difference between the person and the animal which justifies denying that the animal is a person, namely that it is not an object of first-person reference, a self.

The concern many have had is that this proposal creates a mystery. Given that the person and the animal are both thinkers and thinkers at the same level of sophisticated thought, how can it be that the animal is not thinking of itself in the first-person way if the person is? And how can it be that the animal is thinking of something other than itself in the first-person way if the person is not? How can two thinkers that are so alike differ in this way in their cognitive capacities?

The answer to this is that the person and the animal do not differ in their cognitive capacities, they are we may say, cognitively identical. Each is thinking of exactly the things of which the other is thinking, in exactly the same way. As we may put it, unlike you and me, or my Twin Earth double and me, or Hume and Heimson, they are having exactly the same Fregean thoughts. That is, there is a single set of Fregean thoughts such that each is entertaining all and only those thoughts. So each is of thinking of the person in the first-person way, and neither is thinking of the animal in the first-person way. It is because this is so that the animal is not, though the person is, thinking of himself in the first-person way. To the question 'Why is the animal not of thinking of itself in the first- 
person way given that the coincident person is?' the answer is that this must be so given that that they are the same in this respect: namely, that each is thinking of the person in the first-person way and neither is thinking of the animal in the first-person way. So the question for the first-person pronoun revisionist is not how the animal and person can differ in their cognitive capacities, given their coincidence, ${ }^{1}$ but why, given their numerical distinctness, they are cognitively identical, are entertaining exactly the same Fregean thoughts. But the answer to this is twofold. First, numerically distinct things can have many (almost all) things in common. Secondly, from the materialist viewpoint shared by the animalist and the neo-Lockean it is incomprehensible that things like the coincident person and animal, which are microphysically indistinguishable throughout the relevant period (differing only in irrelevant far off past or future respects), could be cognitively distinct, could be thinking about different things or thinking of them in different ways; the mystery would be if they did. ${ }^{2}$

\section{$\underline{\text { References }}$}

Olson, E. 2007 What are We? A Study in Personal Ontology. Oxford: Oxford University Press.

\footnotetext{
${ }^{1}$ If anyone wants to insist that there is a sense which the person and the animal differ in cognitive capacity because only the former has the capacity to know himself first-personally the substantive point is that this is so only in a sense in which it follows from the fact that they cannot differ in their Fregean thoughts. Analogously, if we have the same killing capacities in the sense that there is one and the same individual we can both kill, namely me, so that I can commit suicide and you can't, is that a difference in killing capacities? In one sense it is, in another it isn't. If it is it is only because we can kill all and only the same things that we differ in our killing capacities in respect of our ability to commit suicide.

${ }^{2}$ Compare the grounding objection to constitutionalism (Olson 2007: section 3.1). Olson focuses this objection on the Paradox of Increase (2007: sections 7.3 and 7.4) and asks how two presently coincident wholly material objects (like the person and the animal on the materialist view) can differ in their present capacities for growth. Obviously, they cannot. Nor can they differ in what they are presently thinking about or how they are thinking about them.
} 